\title{
Effects of Reticence, Affect for Communication Channels, and Self-Perceived Competence on Usage of Instant Messaging
}

\author{
Lynne Kelly, James A. Keaten, Michael Hazel, \& \\ Jason A. Williams
}

This study examined the relationship between reticence (Keaten \& Kelly, 2000) and instant messaging (IM), including affect for IM, usage of IM, and self-perceived competence using IM in difficult interpersonal situations. Participants $(\mathrm{N}=336)$ from undergraduate courses responded to self-report measures of reticence, affect for IM, general usage of IM, as well as usage in challenging interpersonal situations, and communication competence. A structural equation model indicated that reduced anxiety and inhibition, IM competence, and increased preparation and control explained $34 \%$ of the variance in frequency of IM use in a difficult personal situation. Results showed that higher levels of reticence were associated with positive affect for IM, which, in turn, increased the likelihood of using IM in a difficult personal situation.

\footnotetext{
Lynne Kelly ( $\mathrm{PhD}$, The Pennsylvania State University, 1982) is a professor in the School of Communication at the University of Hartford. James A. Keaten (PhD, The Pennsylvania State University, 1991) is a professor in the Department of Communication at the University of Northern Colorado. Michael Hazel (PhD, Washington State University, 2004) is an assistant professor in the Department of Communication Arts at Gonzaga University. Jason A. Williams (PhD, University of California, Santa Cruz, 2001) is an assistant professor of psychology at California Polytechnic Institute, San Luis Obispo. Correspondence: Lynne Kelly, School of Communication, University of Hartford, 200 Bloomfield Avenue, West Hartford, CT 06117;
} 
The development of computer-mediated communication (CMC) has sparked research addressing many questions, including who is using what forms of CMC and for what purposes (e.g., Lenhart, Madden, Macgill, \& Smith, 2007; Papacharissi \& Rubin, 2000). Scholars have studied online communication of shy, apprehensive, or reticent individuals, asking whether computer-mediated channels alleviate anxiety and increase frequency of interaction with others (e.g., Kelly, Keaten, \& Palmer, 2003; Roberts, Smith, \& Pollock, 2000; Scealy, Phillips, \& Stevenson, 2002; Sheeks \& Birchmeier, 2007). As predicted, some studies have found that individuals who are shy, reticent, or apprehensive about communication may have a preference for computer-mediated channels of communication (Kelly \& Keaten, 2007; Kelly, Keaten, Larsen, \& West, 2004; Roberts et al., 2000; Stritzke, Nguyen, \& Durkin, 2004).

Scholars have offered several explanations as to why individuals with communication anxiety and avoidance problems prefer online communication. Some have suggested that the lack of physical presence plays a key role and creates the perception of a less evaluative environment, enabling the shy to communicate with greater ease (Roberts et al., 2000; Stritzke et al., 2004). Kelly and Keaten (2005) speculated that high reticent individuals perceive themselves as more competent communicators when online - an explanation supported by the findings of Roberts et al. (2000) and Keaten and Kelly (2008). Keaten and Kelly's (2008) data revealed that the increase in self-perceived competence using e-mail was most strongly associated with the feeling that e-mail increases one's preparation and control over communication. Kelly and colleagues (Keaten \& Kelly, 2008; Kelly, Keaten, Larsen, \& West, 2004) argued that the asynchronous nature of e-mail produces a sense of control that may lead to increased self-perceived competence and decreased anxiety.

Yet, not all forms of CMC are asynchronous. Instant messaging (IM), one of the most popular applications of CMC (Lenhart, Lewis, \& Rainie, 2003; Lenhart, Madden, \& Hitlin, 2005; Lenhart et al., 2007) is synchronous (i.e., both parties are logged on simultaneously and are able to provide immediate responses if they so choose). Much of the extant research has tended to ask questions about shy or apprehensive individuals' use of Internet communication, ignoring this distinction or not including IM (e.g., Birnie \& Horvath, 2002; Roberts et al., 2000; Scealy et al., 2002; Stritzke et al., 2004). However, Rice's (1993) study of traditional and new organizational communication media found that, "The two distinguishing dimensions [of media] appear to be interpersonal-mediated and synchronous-asynchronous" ( $\mathrm{p}$. 479). Participants in Rice's research differentiated among communication media along these dimensions; in fact, the synchronous versus asynchronous distinction has been accepted as an important characteristic of CMC channels. Thus, research that measures use of and attitudes toward specific forms of online communication should enhance understanding of CMC, as well as determine if the synchronousasynchronous distinction continues to be meaningful.

Because the majority of previous research has not focused on how anxious communicators feel about and use IM, the question remains as to whether such individuals have positive affect for IM, viewing it as providing increased preparation and control and enabling more competence than face-to-face (FtF) communication, 
although both are synchronous. This study was designed to address these questions in order to develop more precise conclusions about the impact of communication anxiety on CMC.

\section{Rationale and Hypothesis}

PEW Internet \& American Life Project researchers, Lenhart et al. (2005), concluded that, "Instant messaging has become the digital communication backbone of teen's daily lives" (p. iii). Lenhart et al. (2003) reported that teens like the fact that, with IM, they are able to craft negative messages more carefully. Beyond the PEW studies, there is a small but growing body of research on IM. Studies have focused on, among other topics, linguistic features of IMs (Baron, 2004), construction and use of "away" messages (Baron, Squires, Tench, \& Thompson, 2005; Nastri, Pena, \& Hancock, 2006), motives for IM use (Flanagin, 2005), IM use and perceived intimacy of friends ( $\mathrm{Hu}$, Wood, Smith, \& Westbrook, 2004), social networks of IM users (Bryant, Sanders-Jackson, \& Smallwood, 2006), gender issues (Baron, 2004; Gross, 2004), and problematic IM usage (Lee \& Perry, 2004). Baron (2008) provided a comprehensive review of this line of research, particularly focusing on language in IM and other CMC forms.

As Kelly and Keaten (2007) argued, individuals develop positive or negative affect toward channels of communication through their experiences with and perceptions of these channels. Keaten and Kelly (2008) found that fear of negative evaluation (an important indicator of reticence) was positively associated with affect for the asynchronous channel of e-mail, specifically with perceptions of e-mail affording increased preparation and control, as well as reduced anxiety and inhibition. In contrast, shy, apprehensive, or reticent individuals may develop negative affect for synchronous channels, such as IM, because the timing pressures associated with FtF communication are present. Yet, at the same time, IM does eliminate physical presence and diminishes cues of negative evaluation (Stritzke et al., 2004). Given these competing views, we expected that the association between reticence and affect for IM would be positive but not strong.

Scholars such as Duran (1983), Spitzberg and Cupach (1984), Wiemann (1977), and Rubin (1990) have produced a rich body of literature addressing the question of what constitutes communication competence- a construct about which there has been extensive study and theorizing. That competence involves both effectiveness and appropriateness as a communicator (Canary \& Spitzberg, 1987; Rubin, 1990) is a generally accepted conclusion. Research has found that individuals with communication anxiety and avoidance problems tend to perceive themselves as less communicatively competent (Duran \& Kelly, 1989; Keaten, Kelly, \& Begnal, 1995), and the few studies of actual behavior have, for the most part, supported the self-report findings (for a review of the research, see Daly, Caughlin, \& Stafford, 2009; Pilkonis, 1977a, 1977b).

A premise of much of the research on the relationship of communication anxiety constructs to CMC reviewed earlier is that, because shy, apprehensive, or reticent individuals are less anxious communicating online, they may be more apt to choose 
mediated over FtF channels. Scholars have proposed that self-perceptions of competence may be related to communication channel preferences. For example, O'Sullivan's (2000) model of communication channel preferences included three factors: interactional control; symbolism; and, most germane to this discussion, social skills. O'Sullivan proposed that individuals' preferences for mediated and nonmediated channels are influenced by their self-perceptions of "their ability to carry off the interaction using a specific channel" (p. 413).

Kelly, Keaten, and Finch (2004) found that the problems reticent individuals experience in FtF communication include knowing what to say, timing their remarks, remembering what they wanted to say, choosing the right words, and delivering their remarks well. These problems predicted a preference for using e-mail to interact with faculty (Kelly, Keaten, \& Finch, 2004). Keaten and Kelly (2008) found that a preference for e-mail over FtF interaction was due, in part, to a greater sense of competence online, which was most strongly associated with the perception that e-mail increases preparation and control over communication. In addition, Keaten and Kelly (2008) observed that almost one third of respondents perceived themselves as more competent on e-mail than FtF when dealing with difficult personal situations, and were more likely to use e-mail when confronted with such a situation.

Taken together, these studies suggest that asynchronous mediated channels increase self-perceived communication competence among those with high levels of communication anxiety and avoidance problems. Whether that is the case for synchronous forms of CMC, such as IM, remains to be studied. However, although IM is synchronous, physical presence is eliminated and the demand for an immediate response (as required in FtF interaction) may be lessened somewhat as a result. Thus, the following hypothesis was tested:

H1: Reticence is associated with positive affect and self-perceived competence for using IM, leading to the choice to use IM in a difficult interpersonal situation.

\section{Method}

\section{Participants}

Undergraduate students enrolled in communication or psychology courses at a small Western university and a local community college were recruited for this study $(N=336)$. Of the participants, $40 \%$ were women and $60 \%$ were men. Ages ranged from 17 to 56 , although $81 \%$ of the participants were between 18 and 21 (inclusive). The majority of participants $(79 \%)$ reported that they were European American, followed by Asian Americans (7\%), Hispanics (6\%), and African Americans (3\%).

\section{Instruments}

The survey packet consisted of seven parts, although only the sections that were pertinent to this study are described here. Part 1 consisted of the Reticence Scale-12 (RS-12), a shortened version of the Reticence Scale (Keaten, Kelly, \& Finch, 1997). 
The RS-12 measures six dimensions ( 2 items per dimension) of reticence experienced in social situations: feelings of anxiety, knowledge of conversational topics, timing skills, organization of thoughts, delivery skills, and memory. Each item was measured using a 5-point Likert-type scale, ranging from 1 (strongly disagree) to 5 (strongly agree). Because the primary loadings of 11 of the 12 items were on the first factor and the internal consistency was high $(\alpha=.89)$, the RS-12 was treated as unidimensional. A confirmatory factor analysis indicated that a unidimensional model fit the data well (comparative fit index $[\mathrm{CFI}]=.95$, normed fit index $[\mathrm{NFI}]=.92$, incremental fit index $[\mathrm{IFI}]=.95$, root mean square error of approximation $[$ RMSEA] $=.07)$. All 12 items were summed to produce a reticence score, with a higher score indicating a higher level of reticence $(M=29.60, S D=7.10)$.

Part 2 consisted of items about daily use (in hours per day) for six mediated channels (i.e., e-mail, IM, chat rooms, message boards or bulletin boards, newsgroups or listservs, and MySpace ${ }^{\mathrm{TM}}$ or Facebook). Participants were asked, "Approximately how much time per day do you spend using each of the following forms of computermediated communication?" Usage time was reported in hours (or fractions of hours). If participants did not use a specific form of CMC, they were asked to write down a zero.

The next section assessed amount of IM usage in seven difficult interpersonal situations: "Tell someone something I knew they wouldn't like," "Ask someone to go out with me," "Tell someone that I really like him or her," "Break off a relationship," "Ask a question I was uncomfortable asking in person," 'Let someone know I'm mad at him or her," and "Discuss an embarrassing topic." For each situation, participants responded to, "I have used instant messaging to ...," by choosing from the following response options: many times, a few times, once or twice, never used IM, or never been in this situation or never needed to do this. A principal components analysis $(\lambda>1)$ produced a single-factor solution that explained $55.4 \%$ of the variation in usage scores. The internal consistency of the seven items was high $(\alpha=.87 ; M=18.40, S D=5.08)$.

The fourth section was the Affect for Communication Channels Scale (ACCS; Kelly \& Keaten, 2007), modified to replace e-mail with IM. Participants were asked to record their level of agreement with 21 statements that compare affective predisposition associated with IM versus FtF communication. The instrument consists of 21 items that had previously been shown to be three-dimensional: (a) increased preparation and control (for e-mail; e.g., "I enjoy e-mail because I have more time to organize my ideas"), (b) enhanced meaning and emotion (for FtF; e.g., "With Face-to-Face there is more energy between people"), and (c) reduced anxiety and inhibition (for e-mail; e.g., "When I use e-mail, I say things I wouldn't say face-toface”). Internal consistency estimates, using Cronbach's alpha, were .93, .77, and .81, respectively. A confirmatory factor analysis indicated that the three-factor model fit the data well $(\mathrm{CFI}=.95, \mathrm{NFI}=.91, \mathrm{IFI}=.95, \mathrm{RMSEA}=.06)$. In addition, the factor loadings produced in this study were consistent with the results of two prior studies (see Kelly \& Keaten, 2007) and lend additional support to the stability of the three-dimensional structure of the ACCS. 
Part 5 contained two scales regarding self-perceptions of competence in difficult personal situations (Keaten, Kelly, Pribyl, \& Sakamoto, 2009). One scale measured perceived competence using IM (i.e., "When using instant messaging in a tense or difficult personal situation, I view myself as..."), and the other scale measured perceived competence communicating FtF (i.e., "When talking face-to-face in a tense or difficult personal situation, I view myself as..."). Both competence measures consisted of 7-point semantic differential scales: effective-ineffective, appropriateinappropriate, unskilled-skilled, competent-incompetent, unsuccessful-successful, clear-unclear, and unresponsive-responsive. Each semantic differential scale consisted of seven intervals. A principal components analysis $(\lambda>1)$ produced a single-factor solution for both IM competence $(63.3 \%$ of variance explained) and FtF competence $(60.4 \%$ of variance explained). The internal consistency was high for both IM competence $(\alpha=.90 ; M=32.70, S D=9.09)$ and FtF competence $(\alpha=.87 ; M=38.80, S D=6.66){ }^{1}$

The final section asked participants to provide their gender, age, and ethnicity.

\section{Procedures}

The survey instrument packets were administered along with a cover letter, sanctioned by an institutional review board, explaining the purpose of the study and informing respondents that their responses would be anonymous. The survey took approximately 15 minutes to complete.

\section{Results}

To address $H 1$, a structural equation model (SEM) was constructed using reticence, increased preparation and control, reduced anxiety and inhibition, enhanced

Table 1 Standardized Regression Weights

\begin{tabular}{llcccc}
\hline Criterion variable & Predictor variable & Standard estimate & SE & Critical ratio & $p$ \\
\hline EME & Reticence & -.202 & .029 & -3.66 & .000 \\
RAI & Reticence & .182 & .039 & 3.36 & .000 \\
RAI & EME & -.241 & .072 & -4.49 & .000 \\
IPC & RAI & .657 & .051 & 15.94 & .000 \\
IPC & Reticence & .125 & .037 & 2.99 & .003 \\
IM competence & Reticence & -.170 & .072 & -3.02 & .003 \\
IM competence & IPC & .364 & .081 & 6.54 & .000 \\
IM frequency & RAI & .371 & .011 & 5.98 & .000 \\
IM frequency & IPC & .146 & .009 & 2.27 & .023 \\
IM frequency & IM competence & .252 & .005 & 5.21 & .000 \\
\hline
\end{tabular}

Note. $\mathrm{EME}=$ enhanced meaning and emotion (for face-to-face communication); RAI = reduced anxiety and inhibition (for instant messaging [IM]); IPC = increased preparation and control (for IM). 


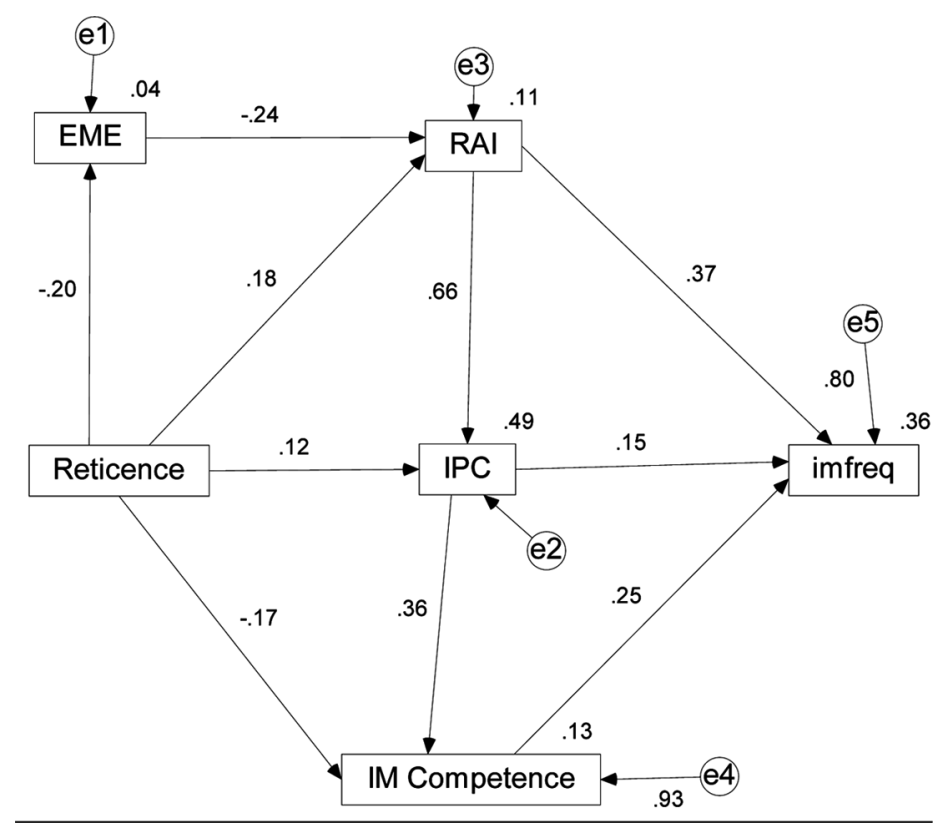

Figure 1 Structural Equation Model of Reticence, Affect for Communication Channels, Competence, and Usage. Note. $\mathrm{EME}=$ enhanced meaning and emotion; RAI = reduced anxiety and inhibition; $\mathrm{IPC}=$ increased preparation and control; imfreq $=$ instant messaging (IM) frequency.

meaning and emotion, self-perceived competence using IM, and use of IM in a difficult personal situation. The results revealed that the model was a fit to the data, $\chi^{2}(5, N=327)=6.94, p=.23(\mathrm{CFI}=.99, \mathrm{NFI}=.98, \mathrm{IFI}=.99, \mathrm{RMSEA}=.03)$. The fit indexes were excellent (CFI, NFI, and IFI >.90; Bentler, 1990; RMSEA <.08; Browne \& Cudeck, 1993). In addition, all paths in the model were statistically significant (see Table 1).

Looking at Figure 1, use of IM in a difficult personal situation was directly explained by reduced anxiety and inhibition $(\beta=.37, p<.001)$, IM competence $(\beta=.25, p<.001)$, and increased preparation and control $(\beta=.15, p<.05)$. IM competence was influenced by increased preparation and control $(\beta=.36, p<$ $.001)$ and reticence $(\beta=-.17, p<.005)$. Increased preparation and control was strongly related to reduced anxiety and inhibition $(\beta=.66, p<.001)$. It is important to note that reticence and enhanced meaning and emotion had indirect effects on frequency of IM use in a difficult personal situation. The SEM explained 36\% of the variation in use of IM in a difficult personal situation.

\section{Discussion}

Some scholars have suggested that the lack of physical presence and perceptions of diminished negative evaluation enable the shy to communicate with greater ease online (Roberts et al., 2000; Stritzke et al., 2004). Alternatively, Kelly and Keaten (2005) speculated that high shy or high reticent individuals perceive themselves as 
more competent communicators when online - an idea supported by Keaten and Kelly's (2008) research. In their work, the increase in self-perceived competence using e-mail was most strongly associated with the increased preparation and control over one's communication due to e-mail being asynchronous. This study was designed to examine whether individuals who experience anxiety about communication have positive affect and self-perceived competence for the synchronous and, among youth especially, highly popular CMC form of IM, and whether those variables impact usage of IM in a difficult interpersonal situation.

Findings from the study enable us to draw several conclusions. First, individuals with communication problems (such as reticence) report positive affect for the mediated channel of IM. Higher levels of reticence are associated with the perception that IM reduces both anxiety and inhibition, and provides more opportunity to prepare, as well as to control communication. Conversely, higher reported reticence is associated with less agreement with the belief that FtF communication is more meaningful and enables more emotional exchange. Although the relationships were modest, they were comparable to those obtained by Kelly and Keaten (2007) in their study examining the relationship of reticence to affect for using e-mail. Although IM is generally considered a synchronous channel of communication, it appears to be perceived by reticent individuals as similar to e-mail in reducing anxiety and inhibition and providing increased preparation and control.

Second, although reticence was found to be related to affect for using IM, it was negatively related to self-perceived IM competence in difficult interpersonal situations, such as breaking up or discussing an embarrassing topic. Findings also indicate that high reticent individuals see themselves as less competent in these types of situations for both FtF and IM channels, although the competence gap for high and low reticents is reduced for IM. Results of the SEM reveal, however, that reticence is positively related to increased preparation and control, which itself is positively related to IM competence in difficult situations. Perhaps, then, reticence has an indirect relationship with self-perceived competence for IM - that is, high reticent individuals associate mediated channels like IM with the ability to prepare and control their communication. It is this sense of increased preparation and control that produces a greater sense of competence on IM compared to FtF interaction. Future research needs to examine further the relationships among these variables.

Results of this study also support the conclusion that perceptions of IM as reducing anxiety and inhibition and increasing preparation and control, along with selfperceived IM competence, predict usage of IM in difficult communication exchanges. Further, reticence appears to have an indirect relationship to usage of IM in these types of situations. Again, reticence is associated with perceptions of increased preparation and control along with perceptions of reduced anxiety and inhibition, which themselves predict IM usage.

Finally, this study raises questions about the asynchronous-synchronous dichotomy often presumed to be a fundamental distinction between communication media. Asynchronous media allow users to respond to messages when it is convenient or desirable for them to do so. Because the other individual is not online at the same 
time and waiting for an immediate response, the person composing a message has the opportunity to carefully craft the message, editing and revising as much as needed before sending. Synchronous media, in contrast, presumably require quick responses because both individuals are online and interacting with one another. Imagine a telephone conversation, for example. Both parties do not have the opportunity to carefully compose their messages, cannot edit messages, and are under some pressure to respond quickly and "get it right" the first time. IM is synchronous online communication, with both communicators online at the same time. The pressure of an immediate response and the lack of opportunity to choose one's words carefully and edit messages before sending should create stress for reticent communicators because of their fear of negative evaluation, their difficulty finding the words they want to say, and their problems with timing their remarks (Kelly, Keaten, \& Finch, 2004). However, our results indicated that reticence was associated with positive affect for IM; it was viewed as reducing anxiety and inhibition, and providing increased preparation and control. If IM is indeed synchronous, it is unclear why reticent individuals perceive it as providing increased preparation and control, in particular. One explanation is that they are using this synchronous medium asynchronously-an observation Baron (2005) made about IM use among college students.

It is plausible that the synchronous versus asynchronous dichotomy established in the early 1990s (e.g., Rice, 1993) is more appropriately viewed as a continuum, as Baron (2008) suggested. That high reticents view IM as affording increased preparation and control suggests that they do not perceive it as a channel requiring immediate responses (as is required in FtF situations). Perhaps, then, IM is seen as less synchronous than FtF communication. Recent research on IM provides evidence that synchronicity represents a continuum. For example, Baron (2005) found that a sample of college students typically multitasked while using IM, often carrying on multiple IM conversations. Students reported that a particular conversation on IM could be synchronous or asynchronous. As Baron (2005) reported, "Users control whether to make a particular conversation active (i.e., synchronous) or to let it lie dormant (i.e., asynchronous)" (p. 13). In another study, Baron's (2004) linguistic analysis of IM conversations revealed an average of four turns per minute, leading her to conclude that, "In many instances, this 'synchronous' form of CMC is being used asynchronously" (p. 417). Norms of usage, therefore, have developed that allow IM users to choose the degree to which it is synchronous.

In drawing these conclusions, it is necessary to acknowledge this study's limitations. For instance, participants were asked to report their competence in difficult interpersonal situations only, rather than more generally. It is possible that obtaining self-reports of general communication competence may have produced different results, particularly because a sizable number of participants, especially high reticent participants, reported not having been in the situations. Future research should include a measure of communication competence that goes beyond assessing competence in these specific contexts. A second limitation is the use of self-reported competence rather than relying on observer or expert evaluations or behavioral measures. The choice to use self-reports, however, was justified by a purpose of the study, which 
was to find out if reticence was related to affect for and usage of IM and, if so, if both affect and usage were associated with individuals' sense of their own competence using IM and FtF communication.

Future research could compare high and low reticent individuals' self-reports and either partner ratings or actual message features as indicators of communication competence in IM. A final limitation is the study focused on IM as the only mediated communication channel. A study in which both IM as a synchronous channel and e-mail as an asynchronous channel are compared directly is warranted, and may provide a further test of the synchronous-asynchronous dichotomy.

\section{Note}

[1] Two independent-samples $t$ tests were conducted to analyze the differences in self-reported competence of participants in a high reticence group (above the 66th percentile; $N=97$ ) compared to a low reticence group (at or below the 33rd percentile; $N=103$ ). Results showed that high reticents $(M=36.10, S D=6.83)$ reported less competence than low reticents $(M=41.50, S D=5.86)$ when discussing a difficult personal situation face to face, $t(193)=-5.91, p<.001\left(\eta^{2}=.15\right)$. High reticents $(M=31.40, S D=9.42)$ also reported less competence than low reticents $(M=34.60, S D=8.09)$ when discussing a difficult personal situation using instant messaging, $t(183)=-2.42, p<.01\left(\eta^{2}=.03\right)$.

\section{References}

Baron, N. S. (2004). See you online: Gender issues in college student use of instant messaging. Journal of Language \& Social Psychology, 23, 397-423.

Baron, N. S. (2005, February). Instant messaging by American college students: A case study in computer-mediated communication. Paper presented at the annual meeting of the American Association for the Advancement of Science, Washington, DC.

Baron, N. S. (2008). Always on: Language in an online and mobile world. New York: Oxford University Press.

Baron, N. S., Squires, L., Tench, S., \& Thompson, M. (2005). Tethered or mobile? Use of away messages in instant messaging by American college students. In R. Ling \& P. Pedersen (Eds.), Mobile communications: Re-negotiation of the social sphere (pp. 293-311). London: Springer-Verlag.

Bentler, P. M. (1990). Comparative fit indices in structural models. Psychological Bulletin, 107, 239-246.

Birnie, S. A., \& Horvath, P. (2002). Psychological predictors of Internet social communication. Journal of Computer-Mediated Communication, 7. Retrieved September 19, 2003, from http://www.ascusc.org/jcmc/vol7/issue4/horvath.html

Browne, M. W., \& Cudeck, R. (1993). Alternative ways of assessing model fit. In K. A. Bollen \& J. S. Long (Eds.), Testing structural equation models (pp. 136-162). Newbury Park, CA: Sage.

Bryant, J. A., Sanders-Jackson, A., \& Smallwood, A. M. K. (2006). IMing, text messaging, and adolescent social networks. Journal of Computer-Mediated Communication, 11, 577-592.

Canary, D. J., \& Spitzberg, B. H. (1987). Appropriateness and effectiveness perceptions of conflict strategies. Human Communication Research, 14, 93-118.

Daly, J. A., Caughlin, J. P., \& Stafford, L. (2009). Correlates and consequences of socialcommunicative anxiety. In J. A. Daly, J. C. McCroskey, J. Ayres, T. Hopf, D. M. A. Sonandré, $\&$ T. K. Wongprasert (Eds.), Avoiding communication: Shyness, reticence, and communication apprehension (3rd ed., pp. 23-50). Cresskill, NJ: Hampton. 
Duran, R. L. (1983). Communicative adaptability: A measure of social communicative competence. Communication Quarterly, 31, 320-326.

Duran, R. L., \& Kelly, L. (1989). The cycle of shyness: A study of self-perceptions of communication performance. Communication Reports, 2, 30-38.

Flanagin, A. J. (2005). IM online: Instant messaging use among college students. Communication Research Reports, 22, 175-187.

Gross, E. F. (2004). Adolescent Internet use: What we expect, what teens report. Applied Developmental Psychology, 25, 633-649.

Hu, Y., Wood, J. F., Smith, V., \& Westbrook, N. (2004). Friendships through IM: Examining the relationship between instant messaging and intimacy. Journal of Computer-Mediated Communication, 10. Retrieved January 11, 2007, from http://jcmc.indiana.edu/vol10/ issuel/hu.html

Keaten, J. A., \& Kelly, L. (2000). Reticence: An affirmation and revision. Communication Education, $49,165-177$.

Keaten, J. A., \& Kelly, L. (2008). "Re: We really need to talk": Affect for communication channels, competence, and fear of negative evaluation. Communication Quarterly, 56, 407-426.

Keaten, J. A., Kelly, L., \& Begnal, C. (1995, November). Effects of the Penn State Reticence Program on communication behavior. Paper presented at the annual meeting of the Speech Communication Association, San Antonio, TX.

Keaten, J. A., Kelly, L., \& Finch, C. (1997). Development of an instrument to measure reticence. Communication Quarterly, 45, 37-54.

Keaten, J. A., Kelly, L., Pribyl, C. B., \& Sakamoto, M. (2009). Fear and competence in Japan and the U.S.: Fear of negative evaluation, affect for communication channels, channel competence and use of computer mediated communication. Journal of Intercultural Communication Research, 38, 23-39.

Kelly, L., \& Keaten, J. A. (2005, November). Explaining the appeal of email to reticent individuals: Development of the Affect for Communication Channels Scale. Paper presented at the annual meeting of the National Communication Association, Boston.

Kelly, L., \& Keaten, J. A. (2007). Development of the Affect for Communication Channels Scale. Journal of Communication, 57, 349-365.

Kelly, L., Keaten, J. A., \& Finch, C. (2004). Reticent and non-reticent college students' preferred communication channels for interacting with faculty. Communication Research Reports, 21, 197-209.

Kelly, L., Keaten, J. A., Larsen, J., \& West, C. (2004, November). The impact of reticence on use of computer-mediated communication II: A qualitative study. Paper presented at the annual meeting of the National Communication Association, Chicago.

Kelly, L., Keaten, J. A., \& Palmer, D. L. (2003, November). The impact of reticence on use of computer-mediated communication. Paper presented at the annual convention of the National Communication Association, Miami Beach, FL.

Lee, K. C., \& Perry, S. D. (2004). Student instant message use in a ubiquitous computing environment: Effects of deficient self-regulation. Journal of Broadcasting \& Electronic Media, $48,399-420$.

Lenhart, A., Lewis, O., \& Rainie, L. (2003). Teenage life online: The rise of the instant-messaging generation and the Internet's impact on friendships and family relationships. In K. M. Galvin \& P. J. Cooper (Eds.), Making connections (3rd ed., pp. 354-361). Los Angeles: Roxbury.

Lenhart, A., Madden, M., \& Hitlin, P. (2005). Teens and technology: Youth are leading the transition to a fully wired and mobile nation (PEW Internet \& American Life Project report). Retrieved September 10, 2005, from http://www.pewinternet.org

Lenhart, A., Madden, M., Macgill, A. R., \& Smith, A. (2007). Teens and social media (PEW Internet \& American Life Project report). Retrieved January 3, 2008, from http://www.pewinternet.org 
Nastri, J., Pena, J., \& Hancock, J. T. (2006). The construction of away messages: A speech act analysis. Journal of Computer-Mediated Communication, 11, 1025-1045.

O'Sullivan, P. B. (2000). What you don't know won't hurt me: Impression management functions of communication channels in relationships. Human Communication Research, 26, 403-431.

Papacharissi, Z., \& Rubin, A. M. (2000). Predictors of Internet use. Journal of Broadcasting \& Electronic Media, 44, 175-196.

Pilkonis, P. A. (1977a). The behavioral consequences of shyness. Journal of Personality, 45, 596-611.

Pilkonis, P. A. (1977b). Shyness, public and private, and its relationship to other measures of social behavior. Journal of Personality, 45, 585-595.

Rice, R. E. (1993). Media appropriateness using social presence theory to compare traditional and new organizational media. Human Communication Research, 19, 451-484.

Roberts, L. D., Smith, L. M., \& Pollock, C. M. (2000). U r a lot bolder on the net. In W. R. Crozier (Ed.), Shyness: Development, consolidation and change (pp. 121-138). New York: Routledge.

Rubin, R. B. (1990). Communication competence. In G. M. Phillips \& J. T. Wood (Eds.), Speech communication: Essays to commemorate the 75th anniversary of the Speech Communication Association (pp. 94-129). Carbondale: Southern Illinois University Press.

Scealy, M., Phillips, J. G., \& Stevenson, R. (2002). Shyness and anxiety as predictors of patterns of Internet usage. CyberPsychology \& Behavior, 5, 507-515.

Sheeks, M. S., \& Birchmeier, Z. P. (2007). Shyness, sociability, and the use of computer-mediated communication in relationship development. CyberPsychology \& Behavior, 10, 64-70.

Spitzberg, B. H., \& Cupach, W. R. (1984). Interpersonal communication competence. Beverly Hills, CA: Sage.

Stritzke, W. G. K., Nguyen, A., \& Durkin, K. (2004). Shyness and computer-mediated communication: A self-presentational theory perspective. Media Psychology, 6, 1-22.

Wiemann, J. M. (1977). Explication and test of a model of communicative competence. Human Communication Research, 3, 195-213. 